\title{
Wuchereria bancrofti infection in Haitian immigrants and the risk of re-emergence of lymphatic filariasis in the Brazilian Amazon
}

\author{
Edson Fidelis da Silva Junior ${ }^{[1]}$, Marcus Vinícius Guimarães de Lacerda[1],[2],[3], \\ Gilberto Fontes ${ }^{[4]}$, Maria Paula Gomes Mourão ${ }^{[1],[2]}$ and Marilaine Martins ${ }^{[2]}$
}

\begin{abstract}
[1]. Programa de Pós-Graduação em Medicina Tropical, Universidade do Estado do Amazonas, Manaus, AM, Brasil.
[2]. Fundação de Medicina Tropical Doutor Heitor Vieira Dourado, Manaus, AM, Brasil. [3]. Instituto de Pesquisa Leônidas \& Maria Deane, Fundação Oswaldo Cruz, Manaus, AM, Brasil. [4]. Universidade Federal de São João del-Rei, Campus Centro Oeste, Divinópolis, MG, Brasil.
\end{abstract}

\begin{abstract}
Introduction: Lymphatic filariasis (LF) is a public health problem in Haiti. Thus, the emigration of Haitians to Brazil is worrisome because of the risk for LF re-emergence. Methods: Blood samples of Haitian immigrants, aged $\geq 18$ years, who emigrated to Manaus (Brazilian Amazon), were examined using thick blood smears, membrane blood filtration, and immunochromatography. Results: Of the 244 immigrants evaluated, $1(0.4 \%)$ tested positive for $W$. bancrofti; $11.5 \%$ reported as having received LF treatment in Haiti. Conclusions: The re-emergence of LF in Manaus is unlikely, due to its low prevalence and low density of microfilaremia among the assessed Haitian immigrants.
\end{abstract}

Keywords: Lymphatic filariasis. Haitian immigrants. Brazilian Amazon.

Lymphatic filariasis (LF) is a neglected disease that affects millions of people in endemic regions of Asia, Africa, and the Americas ${ }^{1}$. In the Americas, the active foci are located in Guyana, Dominican Republic, Haiti, and Brazil' ${ }^{2}$. Haiti accounts for $78.7 \%$ of all LF cases in the continent ${ }^{2}$. In these countries, the causative organism of LF is Wuchereria bancrofti, transmitted by Culex quinquefasciatus in urban areas.

In Brazil, the active focus of LF transmission is concentrated in the City of Recife and some cities in its metropolitan region (Olinda, Paulista, and Jaboatão dos Guararapes) on the Northeastern coast ${ }^{1}$. In the north of the country, the Cities of Belém (Pará State) and Manaus (Amazonas State) were endemic for LF in the past, but are currently considered non-endemic ${ }^{1}$.

In 1949, a study evaluated the existence of LF in Manaus. Of 2,405 individuals examined (3.5\% of the City's population at the time), $2 \%$ were infected with $W$. bancrofti microfilariae (autochthonous cases) $^{3}$. In 1956, another study on LF conducted in Manaus revealed that $0.2 \%$ of the 10,889 individuals examined had $W$. bancrofti microfilariae infection ${ }^{4}$.

With the advancement in mass drug administration (MDA) programs in many LF endemic countries, it is necessary to

Corresponding author: Dra. Marilaine Martins

e-mail: martins.marilaine@gmail.com

Received 4 October 2016

Accepted 25 January 2017 understand the factors that threaten the control and elimination of this disease. Human migration is one of these factors, and there is little information about the role of infected immigrants in developing new LF outbreaks or re-transmission of this disease in areas where the parasite had been eliminated ${ }^{5}$.

Towards the end of 2010, immigrants from Haiti travelled to Brazil from across the border of the western Brazilian Amazon, attracted by the booming economy and the prospect of work in this country ${ }^{6}$. Haiti has highest prevalence of LF in the Americas, and, in recent years, thousands of Haitians have entered Brazil through the border towns of Tabatinga, in the State of Amazonas, and Brasiléia, in the State of Acre ${ }^{6,7}$.

The present study aimed to identify $W$. bancrofti carriers among Haitian immigrants arriving in Manaus, the capital of Amazonas State, Northern Brazil, and the risk of reintroduction of LF in this City.

Individuals aged $\geq 18$ years, who were staying at the Immigrant Ministry shelters in Manaus and who were born in Haiti were included. Immigrants housed in six shelters provided by Manaus (10 de Novembro Park, City Center, 14 de Janeiro Square, Zumbi dos Palmares II, Laranjeiras Park and Dom Pedro Park), with a total population of 250 , were assessed between June 2013 and June 2014.

Blood samples were collected from $10 \mathrm{pm}$ to $1 \mathrm{am}$ at the shelters because of the nocturnal periodicity of $W$. bancrofti microfilariae in the human host's peripheral blood ${ }^{8}$. The techniques of thick blood smears (TBS), polycarbonate 
membrane blood filtration (PMF) and immunochromatographic tests (ICT) were used for LF diagnosis. TBS were prepared on microscope slides from blood samples obtained via finger pricks. Peripheral blood sample $(60-80 \mu \mathrm{L})$ smears obtained were allowed to dry at room temperature. The slides were examined under a light microscope with $40 \mathrm{X}$ objective lenses to detect $W$. bancrofti microfilariae.

Venous blood samples were obtained from each participant for PMF. Using a $10 \mathrm{~mL}$ syringe containing $1 \mathrm{~mL}$ of diluted blood in $9 \mathrm{~mL}$ of saline, filtration was performed using polycarbonate membranes with a $3-\mu \mathrm{m}$ pore diameter. The membranes were examined under a light microscope using 40X objective lenses to detect $W$. bancrofti microfilariae. PMF is particularly used for diagnosing individuals with a low density of microfilariae and for the therapeutic control of patients undergoing specific treatment, which usually eliminates or drastically reduces microfilaremia9.

Blood samples obtained from finger pricks were collected in a microhematocrit tube $(100 \mu \mathrm{L})$ and transferred to the Binax Filariasis Now $^{\circledR}$ card, according to the manufacturer's instructions, to perform ICT for the detection of $W$. bancrofti antigens. After 10 minutes, the results of this qualitative test were evaluated.

Individual data were obtained from each participant, including the patient's name, name of parents, date of birth, gender, marital status, educational level, use of medication for filariasis in Haiti, and the migratory route used to get to Brazil. A total of 244 adults Haitian immigrants, were invited to participate in the study and agreed to be examined. The participants were between 18 and 68 years old ( $34 \pm 8.4$ years).
Most immigrants were between 28 and 32 years of age $(28.7 \%$; $70 / 244)$. Among those evaluated, $74.2 \%$ (181/244) were male, and $25.8 \%(63 / 244)$ were female.

Thick blood smears and polycarbonate membrane blood filtration techniques were used to evaluate all immigrants participating in the study, and the rapid immunochromatography test was used for $32 \%(78 / 244)$ of the randomly selected participants. One immigrant was identified as carrying $W$. bancrofti microfilariae $(0.4 \% ; 1 / 244)$ using the TBS technique. This individual also tested positive on ICT and PMF, and had a microfilaremia of $9 \mathrm{mf} / \mathrm{mL}$ blood (Table 1). The microfilaremic positive immigrant was a 29-year old male native of Gonaives City in Haiti, who worked as a salesperson.

During the study, $11.5 \%$ (28/244) of the immigrants were reported as having received for LF in Haiti between 2009 and 2014 (Table 2). With regard to the education level of the evaluated immigrants, $84.2 \%$ did not complete elementary education, and only $9.6 \%$ had completed higher education.

Different migratory routes were used by the Haitians to enter Amazonas State, Brazil. The commonest route used to reach Manaus was via the Dominican Republic through Colombia, Ecuador, and Peru (170 immigrants). The least common route used was via the Dominican Republic, then through Panama, Colombia, Ecuador, and Peru (17 immigrants).

Among the Haitian cities, the capital Port au Prince was the origin for the largest number of immigrants, with $16.4 \%$ (40/244), followed by Aquin 7.8\% (19/244), Cabaret 7\% (17/244), Anse-a-Galets 6.2\% (15/244), St-Louis du Sud 6.2\% $(15 / 244)$, Croix-des-Bouquets $5.7 \%$ (14/244), and Gonaives $5 \%(12 / 244)$.

TABLE 1

Distribution of Haitian immigrants examined using different laboratory diagnosis methods by age group and gender in the Immigrant Ministry shelters in the City of Manaus, Amazonas State, from June 2013 to June 2014.

\begin{tabular}{|c|c|c|c|c|c|c|c|c|c|c|c|c|c|c|c|}
\hline \multirow{2}{*}{$\begin{array}{l}\text { Age group } \\
\text { (years) }\end{array}$} & \multicolumn{8}{|c|}{ Gender } & \multicolumn{4}{|c|}{ Diagnosis methods } & \multicolumn{2}{|c|}{ Infected } & \multirow{2}{*}{$\begin{array}{c}\text { Parasite load } \\
\text { mf } / \mathrm{mL}\end{array}$} \\
\hline & $\mathbf{n}$ & $\%$ & $\mathbf{n}$ & $\%$ & $\mathbf{n}$ & $\%$ & n & $\%$ & $\mathbf{n}$ & $\%$ & $\mathbf{n}$ & $\%$ & $\mathbf{n}$ & $\%$ & \\
\hline $18-22$ & 15 & 6.1 & 4 & 1.6 & 11 & 4.5 & 15 & 6.1 & 15 & 6.1 & 7 & 2.9 & 0 & 0.0 & 0 \\
\hline $23-27$ & 42 & 17.2 & 11 & 4.5 & 31 & 12.7 & 42 & 17.2 & 42 & 17.2 & 12 & 4.9 & 0 & 0.0 & 0 \\
\hline $33-37$ & 43 & 17.6 & 10 & 4.1 & 33 & 13.5 & 43 & 17.6 & 43 & 17.6 & 14 & 5.7 & 0 & 0.0 & 0 \\
\hline $38-42$ & 40 & 16.4 & 6 & 2.5 & 34 & 13.9 & 40 & 16.4 & 40 & 16.4 & 14 & 5.7 & 0 & 0.0 & 0 \\
\hline $43-47$ & 17 & 7.0 & 5 & 2.0 & 12 & 4.9 & 17 & 7.0 & 17 & 7.0 & 6 & 2.5 & 0 & 0.0 & 0 \\
\hline $48-52$ & 13 & 5.3 & 5 & 2.0 & 8 & 3.3 & 13 & 5.3 & 13 & 5.3 & 7 & 2.9 & 0 & 0.0 & 0 \\
\hline Total & 244 & 100.0 & 63 & 25.8 & 181 & 74.2 & 244 & 100.0 & 244 & 100.0 & 78 & 32.0 & 1 & 0.4 & 9 \\
\hline
\end{tabular}

TBS: thick blood smear; ICT: immunochromatography test; PMF: polycarbonate membrane blood filtration; mf/mL: microfilariae per milliliter of blood. 
TABLE 2

Distribution of Haitian immigrants, by gender, housed in the Immigrant Ministry shelters in Manaus-Amazonas State who received treatment for lymphatic filariasis from 2009 to 2014.

\begin{tabular}{|c|c|c|c|c|c|c|c|c|c|c|c|c|c|c|c|c|}
\hline \multirow{3}{*}{ Gender } & \multirow[b]{3}{*}{$\mathbf{n}$} & \multirow[b]{3}{*}{$\%$} & \multicolumn{14}{|c|}{ Mass treatment of participants in Haiti/year } \\
\hline & & & \multicolumn{2}{|c|}{2009} & \multicolumn{2}{|c|}{2010} & \multicolumn{2}{|c|}{2011} & \multicolumn{2}{|c|}{2012} & \multicolumn{2}{|c|}{2013} & \multicolumn{2}{|c|}{2014} & \multicolumn{2}{|c|}{ Total } \\
\hline & & & $\mathbf{n}$ & $\%$ & $\mathbf{n}$ & $\%$ & n & $\%$ & $\mathbf{n}$ & $\%$ & n & $\%$ & $\mathbf{n}$ & $\%$ & $\mathbf{n}$ & $\%$ \\
\hline Male & 181 & 74.2 & 0 & 0.0 & 1 & 0.6 & 1 & 0.6 & 3 & 1.7 & 9 & 5.0 & 3 & 1.7 & 17 & 9.4 \\
\hline Female & 63 & 25.8 & 2 & 3.2 & 1 & 1.6 & 1 & 1.6 & 3 & 4.8 & 3 & 4.8 & 1 & 1.6 & 11 & 17.5 \\
\hline Total & 244 & 100.0 & 2 & 3.2 & 2 & 2.1 & 2 & 2.1 & 6 & 6.4 & 12 & 9.7 & 4 & 3.2 & 28 & 26.9 \\
\hline
\end{tabular}

The Brazilian Amazon has favorable environmental conditions for the re-emergence of $W$. bancrofti because of the high concentrations of $C$. quinquefasciatus and because there is a lack of basic sanitation in many regions. Furthermore, this region was endemic for $W$. bancrofti in the past ${ }^{1}$. Since the last study on LF in the City of Manaus ${ }^{4}$, almost 60 years ago, in 1956, no research concerning the incidence or prevalence of this disease has been conducted in the City. Since the 1980s, the Brazilian Ministry of Health has reported that Manaus was no longer a focus for the transmission of this disease ${ }^{1}$.

The ongoing migration process of Haitians to Brazil can be worrisome because this could result in W. bancrofti emergence in regions where it never existed or re-emergence in regions where it has been eliminated. In Sri Lanka, immigrants infected by the parasite that causes LF were responsible for the introduction of the disease into previously unknown areas ${ }^{1,10}$. A similar pattern also occurred in the metropolitan area of Recife, northeast coast of Brazil, where cases of LF appeared in previously unaffected areas ${ }^{1,11}$. Parasitic loads in microfilaremic individuals are a determining factor for the maintenance of LF transmission in an area $^{12}$. Leite et al. (2010) have reported that a $W$. bancrofti microfilaremic positive individual, who was formerly a resident in an endemic area, did not establish a new transmission focus after moving to a non-endemic area despite living for more than 10 years in this new locality ${ }^{12}$. The reason for this absence of transmission is that the infected individual had a low density of microfilaremia ( $4 \mathrm{mf} / \mathrm{mL}$ of blood), which was insufficient for the transmission of LF in this new area, despite there being favorable environmental conditions to the introduction of this disease $^{12}$.

In 2010, there was a mass casualty due to an earthquake in Port-au-Prince and throughout the West Department from Haiti, causing more than 222,000 deaths and 300,000 injuries ${ }^{13}$. Many clinics, hospitals, and government ministries were destroyed, as well as thousands of homes and other buildings. Because of this, thousands of Haitians started migrating to other countries for safety and a better life.

In the present study, we observed that the profile of Haitian immigrants who were hosted in Manaus consisted mainly of young individuals aged $28-32$ years. Men represented $74.2 \%$ of those evaluated. Most participants were single, and some men and women reported having children in Haiti. These findings corroborate the information from the National Immigration Council's report of the Brazilian Ministry of Labor, which revealed that $87.1 \%$ of Haitian immigrants who received permission to stay in Brazil were male. Silva in $2013^{7}$ also noted that men represent $88.5 \%$ of Haitian immigrants coming across the Brazilian Amazon border?

The only detected microfilaremic positive immigrant received treatment with diethylcarbamazine citrate ${ }^{9}$. A compulsory notification of this immigrant was made to the epidemiology department of the Dr. Heitor Vieira Dourado Tropical Medicine Foundation and was included in the Disease Information Notification System of the Ministry of Health of Brazil as non-specific filariasis. The State of Amazonas has no notification system for the $W$. bancrofti parasite, as it had not been considered an LF endemic state until recently. This finding is important for the epidemiological surveillance departments of all Brazilian Federal Units, which must remain alert and active in the early detection and control of all LF cases according to the Brazilian Ministry of Health.

Among the 4,000 to 7,000 Haitians who arrived in Manaus between 2010 and 2014, a large number may be infected with $W$. bancrofti microfilariae, raising the possibility of the reemergence of LF into the Amazon. Manaus faces a significant challenge in controlling infectious diseases due to public health issues related to migration and population growth.

Korte et al. ${ }^{14}$ conducted a study in three cities of the western Brazilian Amazon region where in the 1950s few people had allochthonous $W$. bancrofti infections ${ }^{14}$. No humans or mosquitoes were found to be infected with the parasite, indicating that the studied area was not an active focus ${ }^{14}$. It appears that the small number of people infected and the mild nature of the microfilarial infection reported at that time was not sufficient to sustain the transmission of the parasite ${ }^{14}$.

In Haiti, strategies adopted in recent years play an important role in LF elimination. Many Haitians who relocated to Manaus, report of not having received prior treatment for LF and the continuous inflow of immigrants may represent a threat. It is possible that new microfilaremic positive immigrants, with 
higher parasite loads increase the likelihood of infection transmission with insect vectors in the area. Different studies have reached different conclusions about the potential risk of the disease being reintroduced based on $W$. bancrofti parasite loads; therefore, a continuous surveillance is essential for the previously endemic areas or areas at risk for emergence of new transmission foci ${ }^{6}$.

Mass drug administration (MDA) is a measure that helps to reduce parasite loads, prevalence rates, and incidence of LF in endemic countries. The present study revealed that only a portion of the evaluated immigrants had participated in the MDA in Haiti, but according to Oscar et al. (2014), the MDA in Haiti covered all the national territories ${ }^{15}$. Use of techniques that are more sensitive than TBS in diagnosing $W$. bancrofti infection, such as ICT or PMF, did not result in a larger number of microfilariae carriers. Thus, the MDA conducted in Haiti in recent years may have been an effective measure in the reducing LF in the population.

Additional studies in other cities of Brazil that are also receiving Haitian immigrants should be performed to confirm the low frequency of microfilariae carriers in this population. If this result is confirmed, it shows the low risk of reintroduction of the LF in Brazil by Haitian immigrants.

\section{Ethical considerations}

The study was approved by the Ethics Committee for Research on Humans of the Heitor Vieira Dourado Tropical Medicine Foundation $=$ Manaus, Amazonas State, Brazil (16765313.9.0000.0005 registry). All examined immigrant signed the free and informed consent term.

\section{Acknowledgements}

We would like to thank the Manaus immigrant Pastoral, in the person of Sister Santina Peri for assisting in the lodging of the immigrants and being the interpreter of the creole language. We thank the technician and trainees of the FMT-HVD Parasitology Management, Ademir Roberto, Vilma do Nascimento, Alessandra Veigas e Elisa Mangabeira, for their technical support and help on the undertaking of the laboratory exams.

\section{Financial support}

Fundação de Medicina Tropical Heitor Vieira Dourado, Manaus, Amazonas, Brasil. National Counsel of Technological and Scientific Development (CNPq). Process number 478403/2013-5.

\section{Conflict of interest}

The authors declare that there is no conflict of interest.

\section{REFERENCES}

1. Fontes G, Leite AB, de Lima ARV, Freitas H, Ehrenberg JP, da Rocha EMM. Lymphatic filariasis in Brazil: epidemiological situation and outlook for elimination. Parasit Vectors. 2012;5:272. PMC3545725.
2. Centers for Disease Control and Prevention (CDC). Mass drug administration for the elimination of lymphatic filariasis - Portau-Prince, Haiti, 2011-2012. MMWR Morb Mortal Wkly Rep. 2013;62(23):466-8. Accessed 05 March 2015. Available from: http:// www.cdc.gov $/ \mathrm{mmwr} /$ preview $/ \mathrm{mmwrhtml} / \mathrm{mm} 6223 \mathrm{a} 3 . \mathrm{htm}$

3. Deane MP. Sôbre a incidência de filárias humanas em Manaus, Estado do Amazonas. Rev Serv Espec Saude Publica. 1949;2: 849-58.

4. Rachou RG, Lacerda NB. Transmissão da filariose brancroftiana em Manaus (Amazonas). Rev Bras Malariol Doenças Trop. 1956;8(2):369-71. PMID: 13494855.

5. Ramaiah KD. Population migration: implications for lymphatic filariasis elimination programmes. PLoS Negl Trop Dis. 2013;7(3):e2079.

6. Rawlinson T, Siqueira AM, Fontes G, Beltrão RPL, Monteiro WM, Martins M, et al. From Haiti to the Amazon: public health issues related to the recent immigration of Haitians to Brazil. PLoS Negl Trop Dis. 2014;8(5):e2685.

7. Silva SA. Brazil, a new Eldorado for Immigrants? The Case of Haitians and the Brazilian Immigration Policy. Urbanities. 2013;3(2):3-18.

8. Raccurt CP, Mojon M, Hodges WH. Parasitological, serological, and clinical studies of Wuchereria bancrofti in Limbé, Haiti. Am J Trop Med Hyg. 1984;33(6):1124-9.

9. Ministério da Saúde. Secretaria de Vigilância em Saúde. Departamento de Vigilância Epidemiológica. Guia de vigilância epidemiológica e eliminação da Filariose Linfática. Brasília: MS; 2009. $80 \mathrm{p}$.

10. Ramaiah KD, Das PK, Appavoo NC, Ramu KC, Augustin DJ, Vilay Kumar KN, et al. A programme to eliminate lymphatic filariasis in Tamil Nadu State, India: compliance with annual single-dose DEC mass treatment and some related operational aspects. Trop Med Int Health. 2000;5(12):842-7.

11. Medeiros Z, Alves A, Brito JA, Borba L, Santos Z, Costa JP, et al. The present situation regarding lymphatic filariasis in Cabo de Santo Agostinho, Pernambuco, Northeast Brazil. Rev Inst Med Trop São Paulo. 2006;48(5):263-7.

12. Leite AB, Lima ARV, Leite RB, Santos RV, Gonçalves JEL, Rocha EMM, Fontes G. Assessment of family and neighbors of an individual infected with Wuchereria bancrofti from a non-endemic area in the City of Maceió. Brazil. Braz J Infect Dis. 2010;14(2):1258.

13. Hunt MR, Chung R, Durocher E, Henrys JH. Haitian and international responders' and decision-makers' perspectives regarding disability and the response to the 2010 Haiti earthquake. Glob Health Action. 2015;8(1):27969.

14. Korte RL, Fontes G, Camargo JSAA, Rocha EMM, Araujo EAC, Oliveira MZ, et al. Survey of Bancroftian filariasis infection in humans and Culex mosquitoes in the western Brazilian Amazon region: implications for transmission and control. Rev Soc Bras Med Trop. 2013;46:214-20.

15. Oscar R, Lemoine JF, Direny AN, Desir L, Beau de Rochars VEM, Poirier MJP, et al. Haiti National Program for the Elimination of Lymphatic Filariasis - A Model of Success in the Face of Adversity. PLoS Negl Trop Dis. 2014;8(7):e2915. 